\title{
Among the Incarcerated: The Predictive Contributions of Imprisonmemt Status, Perceived Social Support and Personality to Self-Harm Urges
}

\author{
Mfon E Ineme* \\ Department of Psychology, University of Uyo, Nigeria \\ *Corresponding author: Mfon E Ineme, Department of Psychology, University of Uyo, Nigeria
}

Submission: 㭗 April 01, 2018; Published: 僵 May 30, 2018

\begin{abstract}
Empirical evidences have implicated a number of psychological factors in self-harming among prison population globally and in Nigeria. This study, therefore, investigated imprisonment status, perceived social support, and personality factors as predictors of self-harm urges among inmates of a Nigerian prison. It employed ex-post facto design. Multi-stage sampling method was used to select 212 inmates-190 males and 22 females. Revalidated Depression sub-scale of Hospital Anxiety and Depression Scale, Inmates Perceived Social Support Scale, revalidated Eysenck Personality Questionnaire Revised Short Form-Hindi Edition, and Inmates Self-Harm Urges Scale were used to gather data. The $t$-test result $(t(210)=2.70$, $p<0.05)$ showed that non-convicted inmates reported higher self-harm urges than the convicted inmates. There was no significant difference in self-harm urges reported by inmates with low and high perceived social support. Personality factors (extroversion-introversion, psychoticism, and neuroticism) jointly predicted self-harm urges among the inmates ( $2=0.36, F(3,230)=28.63, p<0.05)$, accounting for $36 \%$ of the variance observed in the level of self-harm urges among the inmates studied. It was suggested that psychologists and other mental health experts be employed into the Nigerian Prison Service to help assess the needs, risk factors, and provide the needed interventions..
\end{abstract}

Keywords: Imprisonment status; Perceived social support; Personality; Self-harm urges

\section{Introduction}

The idea and act of harming oneself are not strange to humanity; it is not a recent phenomenon, not a function of the stresses of modern life, but is as old as the human nature itself [1]. People harm or think of harming themselves in various ways (forms) and for different reasons. Some of the known ways or forms of self-harming include cutting or severely scratching one's skin, burning or scalding oneself, hitting oneself or banging one's head, punching things or throwing one's body against walls and hard objects, sticking objects into one's skin, intentionally preventing wounds from healing, taking overdose alcohol and other drugs, and swallowing poisonous substances or inappropriate objects, driving recklessly, binge drinking, taking too many drugs, and having unsafe sex [2]. Some reasons for self-harming include recurrent psychosocial problems [3], poor long term outcome [4], emotional distress [5], poor academic performance [6], and emerging personality disorder [7]. Self-harming is an important public health problem [8], leading to high hospital attendances [9], and reported in many societies across the globe [10], developed, developing, or under-developed. It is an intentional and acute physical self-injury (which include cutting and burning) without intent to die, as it has been found that only a minority of individuals attempt suicide (i.e. intend to die) by cutting or burning [11]. However, it has been estimated that about half of individuals who self-harm also attempt suicide [12], and the parts of the body that are most susceptible to self-harming include, but not restricted to, the legs, arms, and front of the torso because they can be easily reached and easily hidden under clothing [13].

Scientific evidences have proved that self-harming does not occur just once. It is an impulsive, compulsive behavior, a habitual and physically addictive condition physiologically attributed to the fact that chemicals called "endogenous opioids" are released when the body is injured or hurt in any way. The chemical are pleasurable and can make one less sensitive to pain [14]. Thus, people, especially young people come to rely on it not only for physical pleasure or relief through artificially stimulating a 'natural' reaction but also as a way of coping or distracting themselves [14]. Empirical evidences also show that those who self-harm generally would nurse such urges for some time before implementing the act [15], implying that basically, self-harming behaviour starts with the urges. Understanding the etiology of the urges would therefore be a step in the right direction to curbing the propensity for the acts. 
Self-harm has been reported among prison inmates globally and in Nigeria. Prison inmates in Nigeria have reportedly shown self-harming behaviours among other vices [16]. One reason for such behavior, a recent finding from Wealstun prison indicated that bullied inmates deliberately self-harm in a desperate bid to be transferred out of a particular jail to another when they felt unsafe and were often bullied over debts caused by drugs or tobacco [17]. But as is the case in general population, a numbers of factors have been found to influence the behaviour and predispose to selfharming among prison inmates. William \& Adamson [18] found such factors to include imprisonment status (being convicted or not convicted) among other criminological factors. It has been reported that non-convicted (awaiting trial) inmates were more likely to selfharm than the convicted ones and that sometimes such self-injury may be an attempt to seek attention or to manipulate others to attain some goals [19-21].

Equally, lack of social support has been implicated in poor selfregulation and self-harming tendencies [22]. Already, it has been found that psychosocial support contributes to health by protecting from adverse effects of stress and influences health by promoting self-esteem and self-regulation, regardless of the presence of stress [22]. Simply, psychosocial support often takes into consideration the psychological development and well-being of the human person as well as interaction with the social environment. It is often recommended for and/or given to people in traumatic conditions to facilitate participation to their convalescence and prevent pathological consequences of the traumatic situations [22] which could come in the form of lack of proper self-regulation resulting in harm against self [23]. Lehnert [24] holds that imprisonment can be a very difficult time for some people (capable of causing selfdysregulations) and that it is important that they get the help and support they need to see them through the bad times. In a study on perceived social support, Sarason [25] upheld that the individual may not feel satisfied if what the situation offers him/her is not in agreement with what he/she brings into the situation; and that personal relationships grow in a mixture of objective (what happens) and the subjective (what each person is thinking about, able to do, and looking for).

Also, personality factors (traits) have implicated in selfharming. For [7], it is indicative of an emerging personality disorder. DSM-IV TR holds that those with borderline personality have self-harm as a major criterion for their diagnosis [26-29] and without treatment, symptoms may worsen, leading (in extreme cases) to suicide attempts [29]. Investigations using Eysenck's dimensions of personality revealed that males who score high on the P (psychoticism) and the $\mathrm{N}$ (neuroticism) scales are associated with history of self-harm by mutilation. In females, both low $\mathrm{E}$ (extroversion) and high $\mathrm{N}$ (neuroticism) are associated with a history of self-mutilation. High $\mathrm{N}$ scores were also more likely to appear in court (implying high criminality) [18]. Conduct Disorder (a personality condition) has been implicated in self-harming behaviours, increased risk for incarceration, depression, substance abuse, and death by homicide and suicide [30]. In a study, Mark et al. [31] found that for males, high P (psychoticism) scores and high $\mathrm{N}$ (neuroticism) scores were associated with a history of deliberate self-harm (DSH) by mutilation, while in females, both low E (extroversion-introversion) scores and high $\mathrm{N}$ scores were associated with a history of self-mutilation. Also, Haw et al. [32] which implicate psychiatric and personality disorders and their comorbidity in self-harm.

With all these, it could be deduced that imprisonment status, social support, and personality factors have empirically been implicated in self-harm urges. But a vast number of those research were foreign to Nigeria, and more particularly foreign to SouthSouth Nigeria hence the need to investigate the roles of such variables in self-harm urges among prison inmates in Uyo prison in South-South Nigerian with the aim of suggesting workable psychological interventions.

This study hinged on a few theories. One of such theories is Linehan's Bio-psycho-social Theory. Linehan [33] propounded that chronic negative emotions and self-invalidation are the primary factors that predispose Borderline Personality Disorder (BPD) individuals to self-mutilation and suicide attempts. Indeed, evidence suggests that as many as $40 \%-90 \%$ of individuals with BPD either engage in non-suicidal self-injury or make a suicide attempt [27]. The bio-psycho-social theory states that emotion dysregulation results from a combination of high sensitivity or reactivity to emotional stimuli and a deficit in emotion regulation skills (e.g., inability to distract). BPD individuals often engage in impulsive and maladaptive behaviors (including parasuicide) in response to intense emotions [8]. These maladaptive behaviors are either automatic, mood-dependent responses to emotions or attempts to modulate or cope with emotions. Furthermore, individuals fluctuate between extremes of emotional experiencing and emotional inhibition. According to Linehan [33], self-invalidation is learned from environments that invalidate self-generated behaviors and communication of private experiences. These behaviors are often punished, trivialized, disregarded, pathologized, or criticized.

By this theory, inmates who are likely to self-harm hence, experiencing self-harm urges are most likely those who, characteristically have heightened emotional sensitivity, inability to regulate intense emotional responses, and are slow to return to emotional baseline (in event of any emotional upheaval). Such individuals may have grown up with inability to tolerate emotional stressors. This implies that their experiencing self-harm urges is not just caused by their being in prison but would have been an enduring characteristic (personality) which may have begun from adolescence-in an invalidating developmental context. The prison environment, being emotionally disturbing and not making for easy expression of personal emotions, then exacerbates an already existing condition or disposition.

Also, Eysenck [34] propounded a theory which explains the human personality and behaviour intensively and extensively and 
has been described as one of the best known trait theories [35]. Eysenck's theory is a three-dimension theory of personality or a three-factor model which contains the traits of extroversion, neuroticism, and psychoticism. Extraversion-introversion (marked in one of two ways: extroverts are outgoing, other oriented, risktaking, excitement-seeking persons while introverts are reclusive, thoughtful, and quiet), neuroticism (marked in one of two ways: emotionality or stability; emotionality is marked by negative emotions such as being moody or anxious while stability is marked by an even temper, calm existence), and psychoticism (marked by being cruel, cold, and hostile). Eysenck's theory has been the basis for the understanding of human behaviour -adaptive and maladaptive [34, 36-39].

By Eysenck's theory, it is the inability of the individual to regulate the functioning of these systems that would make him/ her to become excessive in any behaviour including maladaptive ones such as such as hurts to self (and to others). The theory tends to imply that the introverts, the highly neurotics (emotional), and the highly psychotics have higher tendencies to experience self-harm urges because by nature, the introverts are thoughtful, preferring solitary places, the neurotic are emotional and so are likely to experience emotional dysfucntioning, and those with high psychoticism are cold and hostile, and self may be become the object of hostility.

The problem warranting this study is the fact that globally, scientific investigations have proved that self-harm (and even completed suicide-the ultimate self-harm) among prison inmates and in the general population is on the increase [21,40]. Finding show that prison inmates often self-harm by slashing, burning, banging their heads, and choking themselves, attributing such to despair due to their inability to cope with their problems which are often magnified [24]. Timms [41] also observed that prison inmates are among the group of persons who are prone selfharming. In Nigeria, mental health experts had reported selfharming behaviour among prison inmates [42]. Particularly, a survey of the Kuje, Kirikiri, and Calabar prisons revealed that the inmates exhibit serious self-harming behaviours among other psychological disturbances [16]. In addition, the result of the focus group discussions (FGD) held in the course of this study with 32 prison inmates and open-ended questions with 97 inmates in Agodi Prisons revealed that not less than $81.25 \%$ of the inmates had experienced self-harm urges at different frequencies and for different reasons. In-depth interview (IDI) with 4 prison staff further confirmed the results. These go to showing the existence of self-harm urges among urges among Nigerian prison inmates and the need to investigate the psychological factors that could possibly predispose to it since self-harming is mental health problem [8]. Also, most of the reports on self-harming in Nigeria are found in media reports and so, indigenous scientific literature in this area is grossly inadequate. There is therefore a gap and an urgent need for indigenous scientific investigation of the aetiology this increasing problem which results will provide a reliable basis for intervention.
So far imprisonment status [21], perceived social support [22], and personality traits $[33,34]$ have been implicated in self-harming behaviour in other parts of the world, but again, the direct study of these factors in relation to self-harming in prison population is inadequate.

It was therefore hypothesize that:

A. Non-convicted prison inmates will report higher selfharm urges than convicted inmates.

B. Prison inmates with low perceived social support will report higher self-harm urges than those with low perceived social support.

C. Personality factors (extraversion-introversion, psychoticism, and neuroticism) will independently and jointly predict self-harm urges among prison inmates.

\section{Method \\ Design}

The study was a cross-sectional survey utilizing ex-post facto design. Ex-post facto design was used because the variable of interest (self-harm urges) had already existed before the study [43]; participants were not manipulated to have low or high selfharm urges.

\section{Setting}

The setting for the study was Uyo prison. The prison yard is located along Willington Bassey Way (former Barracks Road) less than 1 kilometre from the Government House. Uyo Prison shares boundary with the "A" Division Police Station/Barrack. Uyo prison was established in 1954 and is the number one prison in Akwa Ibom State, a medium security prison with a normal capacity for 613 inmates but accommodating an average inmate population of 928 as at the time of this study.

\section{Participants}

A total of 212 inmates participated in the study. Of this number, $190(89.62 \%)$ were males and $22(10.38 \%)$ were females. Their ages ranged between 19 and 64 years. Of the number, $140(66 \%)$ were young (aged between 19 and 29 years) while 72 (33\%) were adults (old).

\section{Sampling method}

A multi-stage sampling method was used in this study; convenience sampling method was used to select the prison from where participants were drawn. The 28 cells of the prison formed the clusters. Random sampling method (balloting) was used to select 15 cells from where the participants were drawn; also the initial sample size of 280 (calculated using the Slovin's method) was randomly selected from the 15 cells (by balloting), each cell having an average 38 inmates, hence an average of 19 participants per cell. Purposive sampling method was used to select the 212 participants that actually participated in the study i.e. only those inmates with 
moderate and severe depressive symptoms participated in the study.

\section{Instruments}

Four instruments were used for the study:

Revalidated depression sub-scale of hospital anxiety and depression scale (HADS): Depression sub-scale of hospital anxiety and depression scale (HADS) developed by Zigmond \& Snaith [44]. Originally the scale consisted of 8 questions relating to anxiety and 8 relating to depression. HADS has been found to be more of psychological screening tool used in predicting probable presence and "caseness" of anxiety and depression rather than diagnostic instrument and has been found to perform well in assessment of anxiety disorder and depression in somatic, psychiatric, and primary care patients and in the general population [45-47]. For the purpose of this study, it was revalidated using 97 prison inmates in Agodi prison and 7 items were found reliable (having a minimum cut-off of .3) with a Cronbach's co-efficient of 0.67 . Scores on this scale range from $0-21$ with scores categorized as follows: normal (0-7), mild (8-10), moderate (11-14), severe (15-21). As used in this study, inmates who scored from 1-10 (normal to mild) did not participate while those who scored from 11-21 (moderate to severe) participated in the study.

4.5.2.Perceived social support scale (PSSS): This is a 15 -item Perceived Social Support Scale (PSSS) developed and validated in the course of this study. It was used to measure satisfaction with the level of social supports received as perceived by the inmates. Following the factor analysis of its initial items, it has three subscales: Sub-scale 1 (items 1 to 6 ) measures perceived social support from the family members with Cronbach's coefficient of .84, Subscale 2 (items 7 to 13) measures perceived social support from prison staff/other inmates with Cronbach's coefficient of .79, and Scale 3 (items 14 to 15 ) measures social perceived support from others like NGOs, religious organizations, etc with Cronbach's coefficient of .55. The general Cronbach's coefficient of scale is 85 . The scale has a norm of 24 established at 2 standard deviations above the mean. Scores below the norm shows low perceived social support while scores from the norm and above showed high perceived social support.

Eysenck personality questionnaire revised short form: Hindi edition (EPQRS-H): The Eysenck Personality Questionnaire Revised Short Form: Hindi edition (EPQRS-H) was developed by Tiwari et al. [48] and was used to measure personality. Initial version of EPQR-S has 48 items and 4 subscales: Extraversion (12 items), Psychoticism (12 items), Neuroticism (12 items), and Lie (12 items). The lie subscale is a control scale in which the whole scale is tested for social desirability bias. Eysenck [36] reported reliabilities for males and females respectively of 0.84 and 0.80 for neuroticism, 0.88 and 0.84 for extraversion, 0.62 and 0.61 for psychoticism, and 0.77 and 0.73 for the lie scale. The EPQRS-H has now been used quite widely [49-51]. For the purpose of this study, it was revalidated using Nigerian samples (97 inmates in Agodi Prison). In the revalidated version, E scale $=9$ items (with Cronbach's co-efficient of 0.76 ), $\mathrm{N}$ scale $=8$ items (with Cronbach's co-efficient of 0.82), $L$ scale=9 items (with Cronbach's co-efficient of 0.56), and $\mathrm{P}$ scale $=9$ items (with Cronbach's co-efficient of 0.76 ), making a total of 35 valid and reliable items with a general Cronbach's coefficient of 0.78 .

Inmates' self-harm urges scale (IS-HUS): This is a 19-item instrument developed by Ineme \& Osinowo [52]. It is designed to measure inmates' urges/tendency to self-harm. It has 3 sub-scales: Sub-scale 1 (items 1 to 11) measures urges for physical harm with Cronbach's coefficient of .93, Sub-scale 2 (items 12 to 15) measures urges for verbal self-harm with Cronbach's coefficient of .84, and Sub-scale 3 (items 16 to 18) measures urges to transfer harms to others with Cronbach's coefficient of .76. The general Cronbach's coefficient of the scale is .83. The norm of the scale is 35 ; norm was established at 2 standard deviations above the mean; scores below the norm showed low self-harm urges while scores above the norm showed high self-harm urges. The reliability study was conducted using 97 inmates in Agodi Prison. The scale has both the English and Yoruba versions but only the English version was used for this study. However, sex, age, and imprisonment status were obtained as demographic factors.

\section{Procedure}

A letter of introduction was obtained from the department of psychology, University of Ibadan and ethical approvals from the Oyo State Research Ethical Review Committee (for the pilot study) and Akwa Ibom State Research Ethical Review Committee (for the main study), in addition to undergoing and completing Basic Course/1 on Human Subject Research Curriculum from West African Bioethics Training Programme and getting certified by Collaborative Institutional Training Initiative (CITI). Also, written permissions were obtained from the Controllers of Prisons, Oyo and Akwa Ibom States Commands. The Deputy Controllers (DCs) in-charge of the yard was then contacted who did formal introductions to the staff of the Welfare Department. The Heads of the Welfare Department conducted an oriented around all the departments, units, offices, and cells in the prison yard. At the end of the orientation exercise, two members of staff of the Welfare Department (a male and a female) were assigned as research assistants on request.

\section{Training of research assistants}

The two members of staff (a male and a female) of the Welfare Department assigned to assist in the conduct of the study were consequently trained on the intricacies and demands of the study. The major areas covered during the training sessions included establishment of rapport, administration of the scales, voluntary participation, perception of inmates taking part in the study as participants and not necessarily as inmates, non-use of coercion or force, etc. They assisted during the initial screening for depressive symptoms and general data collection.

\section{Inclusion/exclusion criteria}

All volunteer inmates were given the opportunity to participate by random selection of the cells and the participants. Those with 
moderate and severe depressive symptoms were actually included in the study. Inmates with clinically diagnosed psychotic symptoms, chronic medical conditions, and overtly unstable behaviours were excluded from the study. Equally, inmates who showed objection to participation at any point were exempted. Inmates with normal to mild depressive symptoms (using HADS) were exempted from participating in the main study.

\section{Ethical considerations}

The major ethical considerations were: confidentiality of data, use local language, beneficence to participants, right to decline from the study at any point, and avoidance of coercion. These were preceded by obtaining of ethical clearance/approval from Oyo and Akwa Ibom States Research Ethical Review Committees.

\section{Administration of instruments}

With the help of the two research assistants and two inmates leaders, the 15 cells were randomly selected and 19 inmates were randomly selected (by balloting) from cell to make the sample size of 280. They were then screened for depressive symptoms using Depression sub-scale of Hospital Anxiety and Depression Scale (HADS) and 47 showed normal or mild depressive symptoms (scoring between 1 and 10 on the scale) and so did not participate further in the study while 233 showed moderate or severe depressive symptoms (scoring between 11 to 21 on the scale). Of this number (233), 9 inmates objected to participation and so withdrew while 224 participated in the next stage of the study by responding to the all the instruments (structured questionnaire comprising demographic variables, EPQR-S, PSSS, and IS-HUS). A total of 12 questionnaires were wrongly completed and so could be used, leaving a total useable instruments of 212. But 97 of them reported low self-harm urges (scoring between 1 and 35 on the self-harm urges scale) while 115 reported high self-harm urges (scoring between 36 and 76). All instructions, guidance, and needed explanations were given repeatedly both in English and local languages (Ibibio, Oron). The administration of the instruments took place in the Prison Chapel; inmates were brought out in succession-one cell after another and each group (inmates from 2 cells) used an average of 63 minutes to complete the instruments. In all, 17 days were used for the administration of the instruments. Their responses were subjected to statistical analysis using SPSS (Version 20.0).

\section{Statistics}

T-test independent samples was used to test for hypotheses 1 and 2 while multiple regression analysis was used to test for hypothesis 3 .

\section{Results}

Hypothesis one stated that non-convicted inmates will report higher self-harm urges than the convicted inmates. This hypothesis was tested using t-test for independent groups and summary of results is presented on (Table 1 ).

Table 1: t-test summary table showing differences between convicted and non-convicted inmates on self-harm urges.

\begin{tabular}{|c|c|c|c|c|c|}
\hline Imprisonment Status & $\mathrm{N}$ & $\mathrm{X}$ & $\mathrm{SD}$ & $\mathrm{Df}$ & $\mathrm{P}$ \\
\hline Non-Convicted & 134 & 25.1 & 13.45 & 210 & 2.7 \\
\hline Convicted & 78 & 21.9 & 10.12 & & \\
\hline
\end{tabular}

The $\mathrm{t}$-test result as presented on (Table 1) $(\mathrm{t}(210)=2.70, \mathrm{p}<.05)$ shows that there was a significant difference between the nonconvicted and the convicted inmates in the level of self-harm urges reported. The non-convicted inmates $(M=25.10, S . D=13.45)$ reported higher self-harm urges than the convicted inmates $(M=21.90, S . D=10.12)$. This result implies that imprisonment status significantly predicted self-harm urges among the inmates sampled. The hypothesis was thus accepted.

Hypothesis two stated that prison inmates with low perceived social support will report higher self-harm urges than those with high perceived social support. This hypothesis was tested using t-test for independent groups and summary of result is presented on (Table 2).

Table 2: t-test summary table showing differences between inmates with low and high perceived social support on selfharm urges.

\begin{tabular}{|c|c|c|c|c|c|c|}
\hline Percd. Social Support & N & X & SD & Df & t & p \\
\hline Low & 79 & 30.08 & 12.93 & 210 & 0.89 & $>0.05$ \\
\hline High & 133 & 28.75 & 8.39 & & & \\
\hline
\end{tabular}

The result on (Table 2) shows that inmates with low perceived social support $(M=30.08, S . D=12.93)$ were not significantly different in the level of self-harm urges compared to inmates with high perceived social support $(M=28.75$, S.D =8.39). This implies that there was no significant difference in the level of self-harm urges reported by inmates with low and high level of perceived social support $(\mathrm{t}(210)=.87, \mathrm{p}>.05)$. This result means that perceive social support did not significantly predict self-harm urges among inmates sampled. The hypothesis was thus rejected.

Hypothesis three stated that personality factors (extroversionintroversion, psychoticism, and neuroticism) will independently and jointly predict self-harm urges among prison inmates. This hypothesis was tested using multiple regression analysis and summary of result is presented on (Table 3). 
Table 3: Summary of multiple regression analysis showing the independent and joint prediction of personality factors on self-harm urges among prison inmates.

\begin{tabular}{|c|c|c|c|c|c|c|c|}
\hline Predictors (Personality Factors) & B & T & p & R & R2 & F & P \\
\hline Extroversion-introversion & -0.05 & -0.91 & $>.05$ & 0.6 & 0.36 & 28.63 & $<.05$ \\
\hline Psychoticism & 0.48 & 8.37 & $<.01$ & & & & \\
\hline Neuroticism & -0.14 & -2.26 & $<.01$ & & & & \\
\hline
\end{tabular}

The result on (Table 3) revealed that personality factors (extroversion-introversion, psychoticism, and neuroticism) jointly predicted self-harm urges $(\mathrm{R} 2=0.36, \mathrm{~F}(3,230)=28.63, \mathrm{p}<.05)$. When combined the extroversion-introversion, psychoticism, and neuroticism accounted for $36 \%$ of the change observed in the self-harm urges reported by the inmates. This revealed that the collective presence of personality factors has significant influence on the self-harm urges among prison inmates studied. The result further revealed that psychoticism $(\beta=.48, t=8.37, p<.01)$ and

Table 4: Logistic regression showing the influence of imprisonment status, perceived social support and personality factors on self-harm urges among prison inmates.

\begin{tabular}{|c|c|c|c|c|c|c|}
\hline & $\boldsymbol{\beta}$ & S.E. & Wald & df & Sig. & Exp( $\boldsymbol{\beta})$ \\
\hline Imprisonment Status & 2.566 & 3481.35 & 5.434 & 1 & 0.995 & 3.301 \\
\hline Extroversion- Introversion & 0.397 & 0.322 & 1.521 & 1 & 0.217 & 1.487 \\
\hline Neuroticism & 2.22 & 0.166 & 1.75 & 1 & 0.186 & 1.803 \\
\hline Psychoticism & 1.237 & 0.239 & 2.98 & 1 & 0.322 & 1.267 \\
\hline Perceived Social Support & -0.004 & 0.064 & 0.004 & 1 & 0.952 & 0.196 \\
\hline Constant & 7.429 & 3481.35 & 0 & 1 & 0.998 & 1684.605 \\
\hline
\end{tabular}

2 Log likelihood $=72.157 \mathrm{a} \quad$ Cox \& Snell R Square $=.534 \quad$ Nagelkerke R Square $=.799$

The result on (Table 4) revealed that inclusion of the independent variables; imprisonment status, extroversionintroversion, neuroticism, psychoticism, and social support to the model increased the level of accuracy from 76.5 to $92.5 \%$. This demonstrated a strong fitted model. The overall significance revealed that the Model Chi square, derived from the likelihood fitted was accurate. The model chi square value of 72.16 was significant. This indicates that the model has a good fit. It is observed from result that the imprisonment status $(\beta=2.57$, wald statistics $=5.43 ; \mathrm{p}<.01)$, extroversion-introversion $(\beta=.39$, wald statistics $=1.52 ; \mathrm{p}<.01)$, neuroticism $(\beta=-2.22$, wald statistics=1.75; $\mathrm{p}<.01)$, and psychoticism $(\beta=1.237$, wald statistics $=2.98 ; \mathrm{p}<.01)$ significantly predicted inmates' self-harm urges. Here, the $\operatorname{Exp(B)}$ or the odds ratio for imprisonment status is 3.301 indicating that non-convicted inmates were 3 times more likely to experience selfharm urges than the convicted inmates, extroversion-introversion increased the likelihood to experience self-harm urges by $48.7 \%$, neuroticism increased the likelihood to experience self-harm urges by $80.3 \%$, while psychoticism increased the likelihood to experience self-harm urges by $26.7 \%$. Perceived social support decreased the chances by $19.6 \%$. Generally, the results indicate that imprisonment status (being non-convicted), being high in introversion, being high in neuroticism, and being high in psychoticism increased neuroticism $(\beta=-.15, t=-2.26, p<.01)$ were significant independent predictors of the self-harm urges among prison inmates. However, extroversion-introversion $(\beta=-.05, \mathrm{t}=-.91, \mathrm{p}>.05)$ was not $\mathrm{a}$ significant independent predictor of self-harm urges among prison inmates studied. The results showed that self-harm urges increased if the prison inmates were high on psychoticism and neuroticism scales.

Further statistical analysis was conducted using logistic regression and summary of the results presented on (Table 4). the likelihood to experience self-harm urges among the inmates studied. These further confirm that imprisonment status and personality factors were significant predictors of self-harm urges among the inmates.

\section{Discussion and Conclusion}

Firstly, the result of this study indicated that the non-convicted prison inmates experienced higher self-harm urges than their convicted counterparts. This result supported earlier findings such as those of $[19,20]$ implicated imprisonment status, among other factors in self-harm urges. It further confirmed the findings that non-convicted inmates involved more in self-harm and reported higher self-harm urges than the convicted ones [53]. This may be in an attempt to attract attention and win the sympathy of prison staff (who may move them to a desired cell or give some benevolence), their attorneys, and the judge when eventually they appear in court; such acts could also be used to feign mental illness (to denote incompetence to stand trial in a court of law). This may also be due to the uncertainties about their fates as go to court the next time, some even lack attorneys or the fees to pay their attorneys while the convicted ones already know and accept their fates; they would have come to terms with realities, understanding that there is probably nothing further they can do than to accept their status 
and serve the jail terms. The uncertainties and anxieties of possible court outcomes are put to rest as they are already convicted.

By the analysis of the second hypothesis, it was found that social support was not a significant predictor of self-harm urges among prison inmates studied. This refuted the earlier findings by some researchers like [22] who held that social support helped in promoting self-esteem and self-regulation, regardless of the presence of stress and trauma. With this finding, it is surmised that Nigerian prison inmates tended to place more values or importance on other things or concerns (such as freedom from the prison) than on any kind of support they were given while still in prison. The finding is however in line with Sarason \& Sarason's [25] finding about perceived social support, which upheld that the individual may not feel satisfied if what the situation offers him/her is not in agreement with what he/she brings into the situation; and that personal relationships grow in a mixture of objective (what happens) and the subjective (what each person is thinking about, able to do, and looking for). Here, what the situation offers may be visits, money, and materials gifts while what the inmates bring into the situation is release, freedom, or discharge - so they remained not satisfied no matter how much of the undesired is offered. Put differently, the inmates may have paid more premiums to their freedom than to any other thing that they may have been given; this was practically very clear and prominent during personal interactions with most of them in the course of this study-their major concerns and lamentations centred around how to leave the prison yard.

Also, following the Biopsychosocial Theory which states that emotion dysregulation which often leads to self harm urges, results from a combination of high sensitivity or reactivity to emotional stimuli and a deficit in emotion regulation skills (e.g., inability to distract) [33], it is explainable that the social support as perceived by the inmates was not enough to alter the emotion dysregulation stimulated by the prison environment and to get them distracted from the stimuli (prison yard discomforts).

Moreover, it was found that those who were high on neuroticism and psychoticism scales reported high self-harm urges. This may be attributed to the fact that those who are neurotic are impulsive, emotional, and reactive while who are psychotic often have cognitive and affective problems resulting in poor perception and inappropriate emotional response; they also experience hallucinate and so self-injuring thoughts may be an inappropriate emotional response or a response to some form of hallucination, especially, auditory hallucination (Davison, 2002). This finding has introduced another dimension of personality involvement in self-harm in addition to earlier findings by scholars like America Psychiatric Association [26], Niedtfeld et al. [28], Robinson [29] which held that those with borderline personality were more likely to self-harm. The finding however confirms the findings of Mark et al. [31] study which results showed that for males, high P (psychoticism) scores and high $\mathrm{N}$ (neuroticism) scores were associated with a history of deliberate self-harm (DSH) by mutilation, while in females, both low E (extroversion-introversion) scores and high $\mathrm{N}$ scores were associated with a history of self-mutilation. It also correlates with the findings of Haw et al. [32] which implicate psychiatric and personality disorders and their comorbidity in self-harm $[54,55]$.

Conclusively, this study investigated imprisonment status, perceived social support, and personality factors as predictor of self-harm urges among Uyo prison inmates. A total of 212 inmates participated in the study and the results showed that nonconvicted inmates and inmates who were high on neuroticism and psychoticism reported higher self-harm urges than the convicted inmates and those low on neuroticism and psychoticism. Extroversion-introversion and perceived social support was not significant predictor of self-harm urges among the inmates studied. This result underscored the need for urgent, direct involvement of psychologists and other mental health experts in the management of the Nigerian prison system-such experts would have to pay professional attention to the risk group i.e. the non-convicted inmates and those who are high on neurticism and psychoticism. This further emphasized the need to psychological assessment of the inmates with few days of admission to help determine their personality traits with the intention of providing intervention where and when needed and avoid self-harm urges becoming fullblown self-harm acts.

\section{References}

1. Nock MA (2010) Self-injury. Annual Review of Clinical Psychology 6: 339-363.

2. Smith M, Segal J (2015) Cutting and self-harm: self-injury help, support and treatment.

3. Hawton K, Houston K, Shepperd R (1999) Suicide in young people: study of 174 cases, aged under 25 years, based on coroners' and medical records. British Journal of Psychiatry 175: 271-276.

4. Fergusson DM, Lynskey MT (1995) Suicide attempts and suicidal ideation in birth cohort of 16 year old New Zealanders. Journal of American Academy Child Adolescents Psychiatry 34: 1308-1317.

5. NHS Choices (2013).

6. Ajapa AA, Issa BA, Buhari OIN, Adeoye PO, Babata AL, et al. (2010) Genital self-mutilation: a case report. Annals of African Medicine 9(1): 31-34.

7. Brent DA, Johnson B, Bartle S, Bridge J, Rather C, et al. (1993) Personality disorder, tendency to impulsive violence, and suicidal behaviour in adolescents. Journal of American Academy Child Adolescents Psychiatry 32: 69-75.

8. Brown M (2005) The behavioral treatment of self-mutilation. A paper presented at XVI congress of the world association for social psychiatry, Vancouver BC, Cambridge University Press, Canada, USA.

9. National Collaborating Centre for Mental Health (2004) Self-harm: the short-term physical and psychological management and secondary prevention of self-harm in primary and secondary care. clinical guideline. Gaskell \& British Psychological Society, London.

10. Green JM, Wood AJ, Kerfoot MJ, Trainor G, Roberts C, et al. (2011) Group therapy for adolescents with repeated self harm: randomized controlled trial with economic evaluation. British Medical Journal 342: 29-39.

11. Wexler L, Weissman MM, Kasl SV (1978) Suicide attempts 1970-1975: updating a United States study and comparisons with international trends. British Journal of Psychiatry 132: 180-185. 
12. Hillbrand M (1995) Aggression against self and aggression against others in violent psychiatric patients. Journal of Consulting and Clinical Psychology 63(4): 668-671.

13. Timberline Knolls (2015) Self-mutilations symptoms and effect.

14. Mental Health Foundation (2012). The truth about self-harm.

15. Connor MJ (2010) The prevalence, nature, and aetiological theories of self-harming behaviour.

16. Adepegba A (2013) Prisons house 750 mentally unstable inmates.

17. Barker V (2009) The politics of imprisonment: how the democratic process shapes the way America punishes offenders. England: Oxford University Press, UK.

18. William JMG, Hassanyeh F (1983) Deliberate self-harm, clinical history and extreme scoring on the EPQ. Personality and Individual Differences 4(3): 347-350.

19. Darke S, Torok M, Kaye S, Ross J (2010) Attempted suicide, self-harm, and violent victimization among regular illicit drug users. Suicide Life Threat Behaviour 40(6): 587-596.

20. Haney C (2004) Prisoners once removed: the impact of incarceration and reentry on children, families, and communities. Urban Institute Press, Washington, DC, USA.

21. Staff MC (2012) Prisoner self-injury on the rise in Canada.

22. Lakey B, Cohen S (2000) Social support theory and measurement.

23. Nock M, Prinstein M (2004) A functional approach to the assessment of self-mutilitative behaviour. Journal of Consulting and Clinical Psychology $72: 885-890$

24. Lehnert S (2011) Worried about self-harm.

25. Sarason IG, Sarason BR (2009) Social support: mapping the constuct Journal of Social and Personal Relationships 26(1): 113-120.

26. American Psychiatric Association (2000) Diagnostic and statistica manual of mental disorders fourth edition text revision (DSM-IV-TR), pp. 645-650.

27. American Psychiatric Association (2004) Practice guidelines for the treatment of psychiatric disorders. Washington, DC, USA.

28. Niedtfeld I, Schulze L, Kirsch P, Herpertz SC, Bohus M, et al. (2010) Affect regulation and pain in borderline personality disorder: a possible link to understanding self-injury. Biological Psychiatry 68: 383-391.

29. Robinson DJ (2005) Disordered personalities. Rapid Psychler Press, USA, pp. 255-310.

30. Loeber R, Farrington DP, Stouthamer-Loeber M, Van Kammen WB (1998) Antisocial behavior and mental health problems: explanatory factors in childhood and adolescence. Lawrence Erlbaum Associates, New Jersey, USA.

31. Mark J, William G, Hassanyeh F (1983) Deliberate self-harm, clinical his tory and extreme scoring on EPQ. Personality and Individual Differences 4(3): 347-350.

32. Haw C, Hawton K, Houston K, Townsends E (2001) Psychiatric and personality disorders in deliberate self-harm patients. The British Journal of Psychiatry 178: 48-54.

33. Linehan MM (1993) Cognitive behavioral treatment of borderline personality disorder. Guilford Press, New York, USA.
34. Eysenck HJ (1967) The biological basis of personality. Springfield, India.

35. Cherry K (2010) Theories of personality. Personality Psychology Study Guide.

36. Eysenck HJ (1992) The definition and measurement of psychoticism. Personality and Individual Differences 13: 757-785.

37. Eysenck HJ (1997) Personality and experimental psychology: The unification of psychology and the possibility of a paradigm. Journal of Personality and Social Psychology 73: 1224-1237.

38. Eysenck HJ, Eysenck MW (1985) Personality and individual differences: A natural science approach, Plenum, New York, USA.

39. Matthews G, Deary IJ, Whiteman MC (2003) Personality traits, ( $2^{\text {nd }}$ edn), Cambridge University Press, UK.

40. The Howard League for Penal Reform (2012) Prison suicide and self-injury.

41. Timms P (2012) Self harm. Royal College of Psychiatrists.

42. Oguntola S (2012) Expert raises alarm on prison inmates with mental illnesses, USA.

43. Kowalczyk D (2015) Ex-post facto design: Definition and examples, USA.

44. Zigmond AS, Snaith RP (1983) The hospital anxiety and depression scale. Acta Psychiatrica Scandinavica 67(6): 361-370.

45. Bjelland I, Dahl AA, Haug TT, Neckelmann D (2002) The validation of hospital anxiety and depression: updated literature review. Journal of Psychosomatic Research 52(2): 69-77.

46. Herrmann C (1997) International experiences with hospital anxiety and depression scale: A review of validation data and clinical results. Journal of Psychosomatic Research 42(1): 17-41.

47. Goodinson WR, Ponsford J, Schonberger M (2009) Validation of hospital anxiety and depression scale to assess depression and anxiety following traumatic brain injury as compare with the structured clinical interview for DSM-IV. Journal of Affective Disorder 144: 1-3.

48. Tiwari T, Signh AL, Signh IL (2009) The short-form revised Eysenck personality questionnaire: A Hindi edition. EPQRS-H. Industrial Psychiatry Journal 18(1): 27-31

49. Aleixo PA, Norris CE (2000) Personality and moral reasoning in young offenders. Personality and Individual Differences 28: 609-623.

50. Blagrove M, Akehurst L (2001) Personality and the modulation of effects of sleep loss on mood and cognition. Personality and Individual Differences 30: 818-828.

51. Chan R, Joseph S (2000) Dimensions of personality, domains of aspiration, and subjective wellbeing. Personality and Individual Differences 28: 347-354.

52. Ineme ME, Osinowo HO (2015) Development and validation of prison inmates self-harm urges scale (IS-HUS): A Psychometric Study. Ife PsychologIA: An International Journal of Psychology in Africa 23(1): 17-31.

53. United States Department of Justice: Federal Bureau of Prisons (2014) About the federal bureau of prisons, USA.

54. William JMG, Hassanyeh F (1983) Deliberate self-harm, clinical history and extreme scoring on the EPQ. Personality and Individual Differences 4(3): 347-350.

55. William EN, Adamson TA (2005) Psychoactive substance use among inmates in a Nigerian prison population. 
Creative Commons Attribution 4.0 International License

For possible submissions Click Here

Submit Article

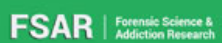 \\ Forensic Science \& Addiction Research \\ Benefits of Publishing with us}

- High-level peer review and editorial services

- Freely accessible online immediately upon publication

- Authors retain the copyright to their work

- Licensing it under a Creative Commons license

- Visibility through different online platforms 